\title{
Article \\ Calculating the Effect of AlGaN Dielectric Layers in a Polarization Tunnel Junction on the Performance of AlGaN-Based Deep-Ultraviolet Light-Emitting Diodes
}

\author{
Yong Wang 1,2,3, Zihui Zhang 4,5 (Dong Guo ${ }^{1,2}$, Yuxuan Chen ${ }^{1,2}$, Yahui Li ${ }^{1,2}$, Zhanbin Qi 1,2, Jianwei Ben ${ }^{1,2}$, \\ Xiaojuan Sun ${ }^{1,2}$ and Dabing $\mathrm{Li}^{1,2, *}$
}

1 State Key Laboratory of Luminescence and Applications, Changchun Institute of Optics, Fine Mechanics and Physics, Chinese Academy of Sciences, Changchun 130033, China; eeywang@ciomp.ac.cn (Y.W.); guolong17@mails.ucas.edu.cn (L.G.); chenyuxuan18@mails.ucas.ac.cn (Y.C.); 18730231183@163.com (Y.L.); qizhanbin2012@163.com (Z.Q.); benjianwei@ciomp.ac.cn (J.B.); sunxj@ciomp.ac.cn (X.S.)

2 Center of Materials Science and Optoelectronics Engineering, University of Chinese Academy of Sciences, Beijing 100049, China

3 State Key Laboratory of High Power Semiconductor Lasers, Chang Chun University of Science and Technology, Changchun 130022, China

4 Key Laboratory of Electronic Materials and Devices of Tianjin, School of Electronics and Information Engineering, Hebei University of Technology, Tianjin 300401, China; zh.zhang@hebut.edu.cn

5 Key Laboratory of Reliability and Intelligence of Electrical Equipment, Hebei University of Technology, Tianjin 300401, China

* Correspondence: lidb@ciomp.ac.cn

check for updates

Citation: Wang, Y.; Zhang, Z.; Guo, L.; Chen, Y.; Li, Y.; Qi, Z.; Ben, J.; Sun, X.; Li, D. Calculating the Effect of AlGaN Dielectric Layers in a

Polarization Tunnel Junction on the Performance of AlGaN-Based Deep-Ultraviolet Light-Emitting Diodes. Nanomaterials 2021, 11, 3328. https://doi.org/10.3390/nano11123328

Academic Editor: Aurora Rizzo

Received: 6 October 2021

Accepted: 2 December 2021

Published: 7 December 2021

Publisher's Note: MDPI stays neutral with regard to jurisdictional claims in published maps and institutional affiliations.

\begin{abstract}
In this work, AlGaN-based deep-ultraviolet (DUV) light-emitting diodes (LEDs) with $\mathrm{AlGaN}$ as the dielectric layers in $\mathrm{p}^{+}-\mathrm{Al}_{0.55} \mathrm{Ga}_{0.45} \mathrm{~N} / \mathrm{AlGaN} / \mathrm{n}^{+}-\mathrm{Al}_{0.55} \mathrm{Ga}_{0.45} \mathrm{~N}$ polarization tunnel junctions (PTJs) were modeled to promote carrier tunneling, suppress current crowding, avoid optical absorption, and further enhance the performance of LEDs. AlGaN with different $\mathrm{Al}$ contents in PTJs were optimized by APSYS software to investigate the effect of a polarization-induced electric field $\left(E_{p}\right)$ on hole tunneling in the PTJ. The results indicated that $\mathrm{Al}_{0.7} \mathrm{Ga}_{0.3} \mathrm{~N}$ as a dielectric layer can realize a higher hole concentration and a higher radiative recombination rate in Multiple Quantum Wells (MQWs) than $\mathrm{Al}_{0.4} \mathrm{Ga}_{0.6} \mathrm{~N}$ as the dielectric layer. In addition, $\mathrm{Al}_{0.7} \mathrm{Ga}_{0.3} \mathrm{~N}$ as the dielectric layer has relatively high resistance, which can increase lateral current spreading and enhance the uniformity of the top emitting light of LEDs. However, the relatively high resistance of $\mathrm{Al}_{0.7} \mathrm{Ga}_{0.3} \mathrm{~N}$ as the dielectric layer resulted in an increase in the forward voltage, so much higher biased voltage was required to enhance the hole tunneling efficiency of PTJ. Through the adoption of PTJs with $\mathrm{Al}_{0.7} \mathrm{Ga}_{0.3} \mathrm{~N}$ as the dielectric layers, enhanced internal quantum efficiency (IQE) and optical output power will be possible.
\end{abstract}

Keywords: light emitting diodes; tunnel junction; polarization; AlGaN

\section{Introduction}

AlGaN-based deep-ultraviolet (DUV) light-emitting diodes (LEDs) have many advantages, including environmental protection, low power consumption, Hg-free material, compact size, controllable wavelength, and a long lifetime, and they can be applied in the fields of disinfection, sterilization, purification, biomedicine, gas sensing, optical data storage, non-line-of-sight communication, identification of hazardous biological agents and so on [1]. AlGaN-based DUV LEDs with a short wavelength of $210 \mathrm{~nm}$ [2] and an improved external quantum efficiency (EQE) of 20.3\% (for $275 \mathrm{~nm}$ ) [3] have been achieved. However, the EQE is still lower than that of GaN-based blue and green LEDs, and the EQE drops dramatically with decreasing wavelength [1]. As is well-known, the EQE is determined by the internal quantum efficiency (IQE) and the light extraction efficiency (LEE), 
where the IQE is determined by the material's quality [4], the carrier injection [5], and the recombination [6]; and the LEE is determined by the total internal reflection (TIR) [7], the optical absorption [7], and the optical polarization [8,9].

In order to improve the EQE, high-efficiency carrier injection is required to realize high-performance AlGaN-based DUV LEDs. However, it is difficult to achieve highefficiency doping, particularly p-type doping, in AlGaN with a high $\mathrm{Al}$ content $[10,11]$. In addition, AlGaN has much lower hole mobility than electron mobility (electron mobility of $\sim 300 \mathrm{~cm}^{2} / \mathrm{V} \cdot \mathrm{s}$ and hole mobility of $\sim 14 \mathrm{~cm}^{2} / \mathrm{V} \cdot \mathrm{s}$ at room temperature for unintentionally doped AlN [12,13]), which results in low hole injection efficiency and high electron leakage [5,14-23]. Moreover, poor ohmic contact between AlGaN and the electrode will increase the series resistance of an LED. Furthermore, the use of a horizontal electrode structure results in a very strong current crowding effect in the p-type side of an LED [24]. The vertical electrode structure is an alternative solution to suppress the current crowding effect $[25,26]$. However, there will be more difficulties and challenges in fabricating the vertical LEDs. In order to improve the current spreading and suppress the current crowding effect, some approaches, such as improving the design of the hole injection layer [27], optimization of the mesa area size to adjust the current distribution [28], enhancing the conductivity of the contact layer with the p-electrode [27], transparent p-side electrode fabrication [7,29], and use of a tunnel junction (TJ) or a polarization TJ (PTJ) [30-41] have been proposed.

A TJ is a heavily doped $\mathrm{p}^{+}-\mathrm{n}^{+}$junction with a thickness of only some $10 \mathrm{~nm}$. When an LED is operated at a forward biased voltage, the top TJ is operated at a reverse biased voltage, so the electrons can tunnel from the $\mathrm{p}^{+}$-side valence band into the $\mathrm{n}^{+}$-side conduction band. In order to reduce the resistance of the TJ, the heavy doping electron and hole concentrations are commonly over $1 \times 10^{20} \mathrm{~cm}^{-3}$. A PTJ is a $\mathrm{p}^{+}-\mathrm{i}-\mathrm{n}^{+}$heterojunction, in which the built-in electric field $\left(E_{b}\right)$ is modulated by polarization induced electric field $\left(E_{p}\right)$ due to the existence of spontaneous polarization and piezoelectric polarization in the $\mathrm{p}^{+}-\mathrm{i}-\mathrm{n}^{+}$ heterojunction. Therefore, the coupled electric field $\left(E_{c}\right)$ comes from the contributions of not only $E_{b}$ but also $E_{p}$. The integration of a TJ or a PTJ in an LED can effectively enhance the hole injection efficiency, and PTJs can further promote hole tunneling by introducing $E_{p}$. In addition, it can suppress the current crowding effect, improve lateral current spreading, and further enhance the uniformity of the top emitting light of the LED, which is possible through the contribution of its relatively high resistance. Moreover, it uses a low-resistivity n-type material instead of a high-resistivity p-type material as the top contact with the anode of the LED, which is very advantageous to ohmic contact. Moveover, it can be applied in multi-color LEDs [42,43], micro LEDs [44] and stacked laser diodes (LDs) [45]. Although there are many advantages, fabricating TJs or PTJs with heavy doping electron and hole concentrations (over $1 \times 10^{20} \mathrm{~cm}^{-3}$ ) is very challenging.

In 2001, an InGaN-based blue LED with a $\mathrm{p}^{+}-\mathrm{GaN} / \mathrm{n}^{+}-\mathrm{GaN}$ TJ was reported, with an optical output power about twice that of conventional LEDs without a TJ [32]. However, the forward voltage of the LED was accordingly increased from 3.9 to $4.9 \mathrm{~V}$, which was caused by the relatively high resistance in TJ. A TJ has a positive impact on the lateral current spreading but has a negative impact on the forward voltage. Therefore, it is crucial to improve the tunneling efficiency by adopting PTJs. In 2013, an InGaN-based blue LED with a $\mathrm{p}^{+}-\mathrm{GaN} / \mathrm{In}_{0.15} \mathrm{Ga}_{0.85} \mathrm{~N} / \mathrm{n}^{+}-\mathrm{GaN}$ PTJ was reported, and improved performance was achieved [35]. Polarization can induce high densities of positive and negative sheet charges at the $\mathrm{p}^{+}-\mathrm{GaN} / \mathrm{InGaN}$ and $\mathrm{InGaN} / \mathrm{n}^{+}-\mathrm{GaN}$ interfaces, which originate from spontaneous polarization and piezoelectric polarization in InGaN along the c-orientation [46]. The high density of polarization induced sheet charges at the $\mathrm{p}^{+}-\mathrm{GaN} / \mathrm{InGaN}$ and $\mathrm{InGaN} / \mathrm{n}^{+}-\mathrm{GaN}$ interfaces can build up $E_{p} . E_{p}$ has a direction along the [000-1] orientation, in the same direction as $E_{b}$. Therefore, $E_{c}$ comes from the contributions of not only $E_{b}$ but also $E_{p}$, 
which can be enhanced by optimizing $E_{p}$ in the PTJ to improve the tunneling efficiency. The intensity of $E_{c}$ in a PTJ can be formulated as follows:

$$
E=e \times\left|\frac{N_{\text {dopant }} \times L_{\text {depletion }} \pm \sigma_{p}}{\varepsilon_{r} \times \varepsilon_{0}}\right|
$$

where $E$ is the intensity of $E_{c}$ in PTJ, $e$ is the value of a unit of electronic charge, $\varepsilon_{0}$ is the absolute dielectric constant, $\varepsilon_{r}$ is the average relative dielectric constant for the PTJ, $N_{\text {dopant }}$ is the ionized dopant concentration in the space charge region, $L_{\text {depletion }}$ is the depletion region's width, and $\sigma_{p}$ is the polarization-induced sheet charge density. The symbol " \pm " represents the direction of $E_{p}$. The symbol "+" represents the same direction as $E_{b}$, and the symbol " - " represents the reverse direction to $E_{b}$. According to the expression in Equation (1), $E$ can be determined by the factors $N_{\text {dopant }}, L_{\text {depletion }}, \sigma_{p}$, and $\varepsilon_{r}$.

It is necessary to point out that $\varepsilon_{r}$ is the inherent constant of a material. For InGaN, there is a linear relationship between $\varepsilon_{r}$ and the In content of InGaN, and $\varepsilon_{r}$ will become larger with an increase in the In content of InGaN. In addition, there is strong optical absorption in the PTJ when the In content of InGaN in the PTJ is higher than that in the active region, as it is quite disadvantageous to the LEE of an LED. AlGaN has a lower $\varepsilon_{r}$ than InGaN, and the $\varepsilon_{r}$ becomes small with an increase in the $\mathrm{Al}$ content of AlGaN. This means that $\mathrm{AlGaN}$ as the dielectric layer of a PTJ is superior to $\mathrm{InGaN}$ as the dielectric layer of a PTJ for enhancing the intensity of $E_{c}$, promoting hole tunneling and avoiding optical absorption, as is very advantageous to the IQE and LEE of an AlGaN-based DUV LED.

However, there is still an inadequate view that $\mathrm{AlGaN}$ as the dielectric layer of PTJ cannot enhance the intensity of $E_{c}$, due to the reverse direction of $E_{p}$ compared with $E_{b}$. As a result, there are few reports on AlGaN as the dielectric layer of PTJs in LEDs. In 2017, InGaN-based near-ultraviolet (NUV) LEDs with $\mathrm{p}^{+}$-GaN/AlGaN $/ \mathrm{n}^{+}$-GaN PTJs were optimized, and enhanced LED performance was achieved. This was the first report on the use of AlGaN as a dielectric material of a PTJ [36,37].

Additionally, the difficulty of heavy doping (a carrier concentration of over $1 \times 10^{20} \mathrm{~cm}^{-3}$ ) in a PTJ has slowed down the progress of research into AlGaN-based DUV LEDs with PTJ. However, the research into AlGaN-based DUV LEDs with PTJs never stopped. In 2018, an AlGaN-based DUV LED with a $\mathrm{p}^{+}-\mathrm{Al}_{0.65} \mathrm{Ga}_{0.35} \mathrm{~N} / \mathrm{In}_{0.2} \mathrm{Ga}_{0.8} \mathrm{~N} /$ graded $\mathrm{n}^{+}$-AlGaN PTJ $\left(\mathrm{p}^{+}=5 \times 10^{19} \mathrm{~cm}^{-3}\right.$ and $\left.\mathrm{n}^{+}=1 \times 10^{20} \mathrm{~cm}^{-3}\right)$ was grown and fabricated, with a wavelength of $287 \mathrm{~nm}$, a forward voltage of $10.5 \mathrm{~V}$, and an optical output power of $54.4 \mathrm{~W} / \mathrm{cm}^{2}$ at a current density of $1 \mathrm{kA} / \mathrm{cm}^{2}$ [34-36]. In 2021, an AlGaN-based DUV LED with a $\mathrm{p}^{+}-\mathrm{GaN} / \mathrm{n}^{+}$-AlGaN PTJ was grown and fabricated, with a wavelength of $245 \mathrm{~nm}$, a maximum EQE of $0.35 \%$ and a wall-plug efficiencies (WPE) of $0.21 \%$ [36]. It was proven that high-performance AlGaN-based DUV LEDs with PTJs can be achieved. However, InGaN or GaN as the dielectric layer of a PTJ is quite unsuitable for AlGaN-based DUV LED due to strong optical absorption in PTJ. $\mathrm{AlGaN}$ has a lower $\varepsilon_{r}$ and a lower optical absorption than InGaN. This means that $\mathrm{AlGaN}$ is superior to InGaN as the dielectric layer of PTJ for promoting hole tunneling, suppressing current crowding, increasing current spreading, and avoiding optical absorption of the PTJ in AlGaN-based DUV LEDs.

In this work, AlGaN-based DUV LEDs with $\mathrm{AlGaN}$ as the dielectric layers in $\mathrm{p}^{+}$ $\mathrm{Al}_{0.55} \mathrm{Ga}_{0.45} \mathrm{~N} / \mathrm{AlGaN} / \mathrm{n}^{+}-\mathrm{Al}_{0.55} \mathrm{Ga}_{0.45} \mathrm{~N}$ PTJs were proposed. AlGaN with different $\mathrm{Al}$ content in PTJs was optimized to investigate the effect of $\mathrm{p}^{+}-\mathrm{Al}_{0.55} \mathrm{Ga}_{0.45} \mathrm{~N} / \mathrm{Al}_{\mathrm{x}} \mathrm{GaN} / \mathrm{n}^{+}$. $\mathrm{Al}_{0.55} \mathrm{Ga}_{0.45} \mathrm{~N}$ PTJs on the performance of AlGaN-based DUV LEDs, where $\mathrm{x}=0.4,0.55$, and 0.7. The output characteristics of the AlGaN-based DUV LEDs including the forward voltage, optical output power, IQE and WPE were characterized. APSYS software was used to conduct a finite element analysis of the electrical, optical, and thermal properties of the LEDs.

\section{Research Methods and Physical Models}

AlGaN-based DUV LEDs for Structures A, B, and C were designed, as shown in Figure 1. The basic structures include a c-plane sapphire substrate, a $1 \mu \mathrm{m}$ AlN buffer layer, 
a $2 \mu \mathrm{m} \mathrm{n}-\mathrm{Al}_{0.55} \mathrm{Ga}_{0.45} \mathrm{~N}$ layer $\left(\mathrm{n}=5 \times 10^{19} \mathrm{~cm}^{-3}\right)$, a $50 \mathrm{~nm} \mathrm{n}$-AlGaN grading layer with the $\mathrm{Al}$ content ranging from 0.55 to $0.85\left(\mathrm{n}=5 \times 10^{19} \mathrm{~cm}^{-3}\right)$, a $10 \mathrm{~nm} \mathrm{n}-\mathrm{Al}_{0.85} \mathrm{Ga}_{0.15} \mathrm{~N}$ hole blocking layer (HBL) $\left(\mathrm{n}=5 \times 10^{19} \mathrm{~cm}^{-3}\right)$, five pairs of multiple quantum wells (MQWs) with a $5 \mathrm{~nm}$ undoped $\mathrm{Al}_{0.55} \mathrm{Ga}_{0.45} \mathrm{~N}$ quantum barrier $(\mathrm{QB})$ and a $1.5 \mathrm{~nm}$ undoped $\mathrm{Al}_{0.4} \mathrm{Ga}_{0.6} \mathrm{~N}$ quantum well (QW), a $10 \mathrm{~nm}$ p- $\mathrm{Al}_{0.85} \mathrm{Ga}_{0.15} \mathrm{~N}$ electron blocking layer (EBL) $\left(\mathrm{p}=5 \times 10^{19} \mathrm{~cm}^{-3}\right)$, a $50 \mathrm{~nm} \mathrm{p}$-AlGaN grading layer with the $\mathrm{Al}$ content ranging from 0.85 to $0.55\left(\mathrm{p}=5 \times 10^{19} \mathrm{~cm}^{-3}\right)$, and a total of $322 \mathrm{~nm}$ for the top layers. For all structures, the bottom layers were the same and the $322 \mathrm{~nm}$ top layers were different. For Structure A (conventional TJ, no polarization layer), the top layers were an $11 \mathrm{~nm}$ $\mathrm{p}^{+}-\mathrm{Al}_{0.55} \mathrm{Ga}_{0.45} \mathrm{~N}\left(\mathrm{p}^{+}=1 \times 10^{20} \mathrm{~cm}^{-3}\right) / 11 \mathrm{~nm} \mathrm{n}^{+}-\mathrm{Al}_{0.55} \mathrm{Ga}_{0.45} \mathrm{~N} \mathrm{TJ}\left(\mathrm{n}^{+}=1 \times 10^{20} \mathrm{~cm}^{-3}\right)$ and a $300 \mathrm{~nm} \mathrm{n}-\mathrm{Al}_{0.55} \mathrm{Ga}_{0.45} \mathrm{~N}$ contact layer $\left(\mathrm{n}=5 \times 10^{19} \mathrm{~cm}^{-3}\right)$. For Structure B (PTJ), the top layers were a $10 \mathrm{~nm} \mathrm{p}^{+}-\mathrm{Al}_{0.55} \mathrm{Ga}_{0.45} \mathrm{~N}\left(\mathrm{p}^{+}=1 \times 10^{20} \mathrm{~cm}^{-3}\right) / 2 \mathrm{~nm} \mathrm{Al}_{0.4} \mathrm{Ga}_{0.6} \mathrm{~N} / 10$ $\mathrm{nm} \mathrm{n}{ }^{+}-\mathrm{Al}_{0.55} \mathrm{Ga}_{0.45} \mathrm{~N}\left(\mathrm{n}^{+}=1 \times 10^{20} \mathrm{~cm}^{-3}\right)$ PTJ and a $300 \mathrm{~nm} \mathrm{n}-\mathrm{Al}_{0.55} \mathrm{Ga}_{0.45} \mathrm{~N}$ contact layer $\left(\mathrm{n}=5 \times 10^{19} \mathrm{~cm}^{-3}\right)$. For Structure $\mathrm{C}(\mathrm{PTJ})$, the top layers were a $10 \mathrm{~nm} \mathrm{p}-\mathrm{Al}_{0.55} \mathrm{Ga}_{0.45} \mathrm{~N}$ $\left(\mathrm{p}^{+}=1 \times 10^{20} \mathrm{~cm}^{-3}\right) / 2 \mathrm{~nm} \mathrm{Al}_{0.7} \mathrm{Ga}_{0.3} \mathrm{~N} / 10 \mathrm{~nm} \mathrm{n}^{+}-\mathrm{Al}_{0.55} \mathrm{Ga}_{0.45} \mathrm{~N}\left(\mathrm{n}^{+}=1 \times 10^{20} \mathrm{~cm}^{-3}\right) \mathrm{PTJ}$ and a $300 \mathrm{~nm} \mathrm{n}-\mathrm{Al}_{0.55} \mathrm{Ga}_{0.45} \mathrm{~N}$ contact layer $\left(\mathrm{n}=5 \times 10^{19} \mathrm{~cm}^{-3}\right)$. Si and $\mathrm{Mg}$ were used to supply the electrons and holes in the $\mathrm{n}$ - and p-layers and the TJ. The anode of the LED was the ohmic contact with the top layer, and the mesa size was set to $300 \times 300 \mu \mathrm{m}^{2}$, with an anode size of $300 \times 50 \mu \mathrm{m}^{2}$ and a cathode size of $300 \times 70 \mu \mathrm{m}^{2}$.

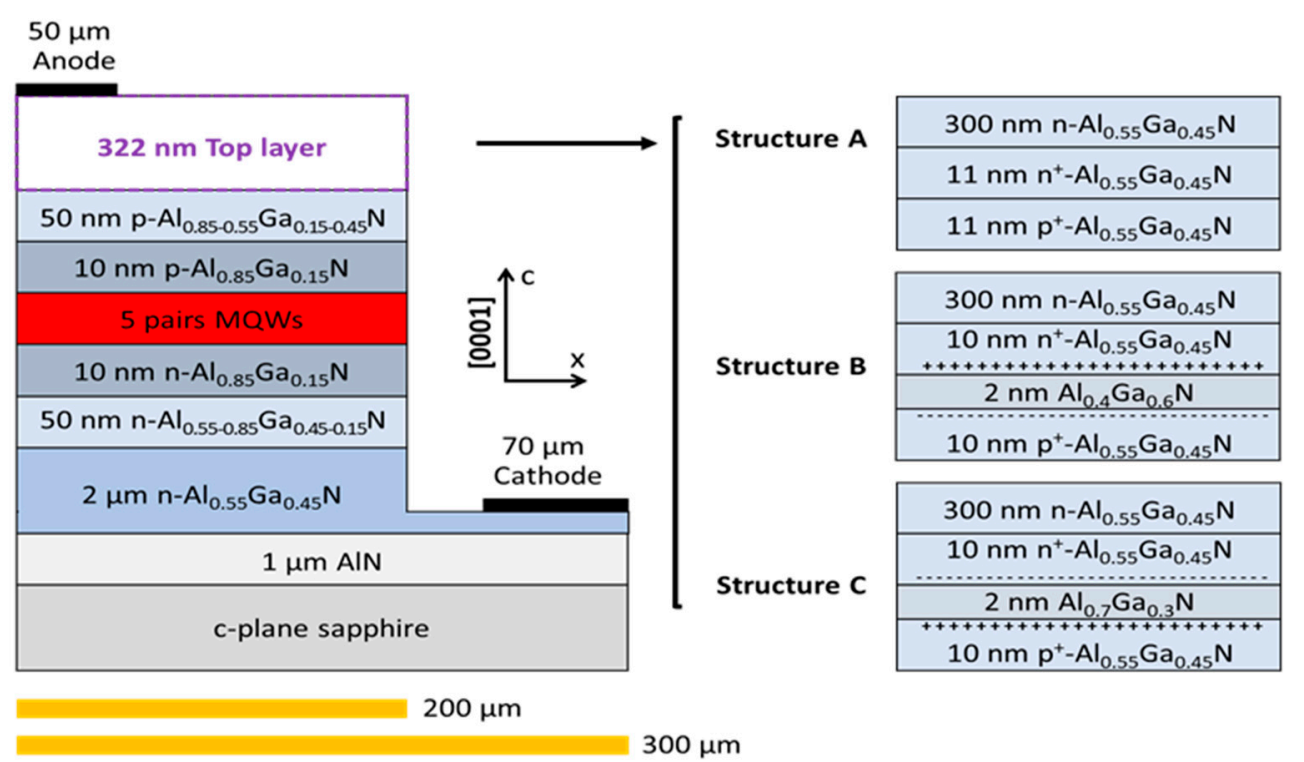

Figure 1. LED structures and the different top layers of Structures A, B, and C.

APSYS software (APSYS-2017, Crosslight Software Inc. Vancouver, Canada) was used to simulate the LEDs. In the simulation, the current continuity equations, Poisson equations, and Schrödinger equations would be solved with proper boundary conditions. The following parameters were set: an Auger recombination coefficient of $1 \times 10^{-42} \mathrm{~m}^{6} / \mathrm{s}$ [35,47], a Shockley-Read-Hall (SRH) lifetime of $1 \times 10^{-8} \mathrm{~s}$ [48,49], an energy band offset ratio $\left(\Delta \mathrm{E}_{\mathrm{C}} / \Delta \mathrm{E}_{\mathrm{V}}\right)$ of 0.5 [50,51], a [0001] polarization level of $40 \%$ [46,52,53], effective masses of the electrons and holes for GaN and AlN [54], and an ambient temperature of $300 \mathrm{~K}$. The effective masses of the tunneling particles in the TJs were $0.230 m_{0}, 0.225 m_{0}$, and $0.234 m_{0}$ for Structures A, B, and C, respectively; $m_{0}$ is the free electron mass. Other parameters of III-nitride based semiconductors can be found elsewhere [55].

\section{Results and Analysis}

Figure 2 shows the distributions of the electric fields (Figure 2a-c), the charged state densities of the space charges (Figure 2d), and the charged state densities of the fixed space 
charges at the interfaces (Figure 2e) in the TJs for Structures A, B, and C at a bias voltage of $0 \mathrm{~V} . \mathrm{N}$ is the charged state density of the space charge.
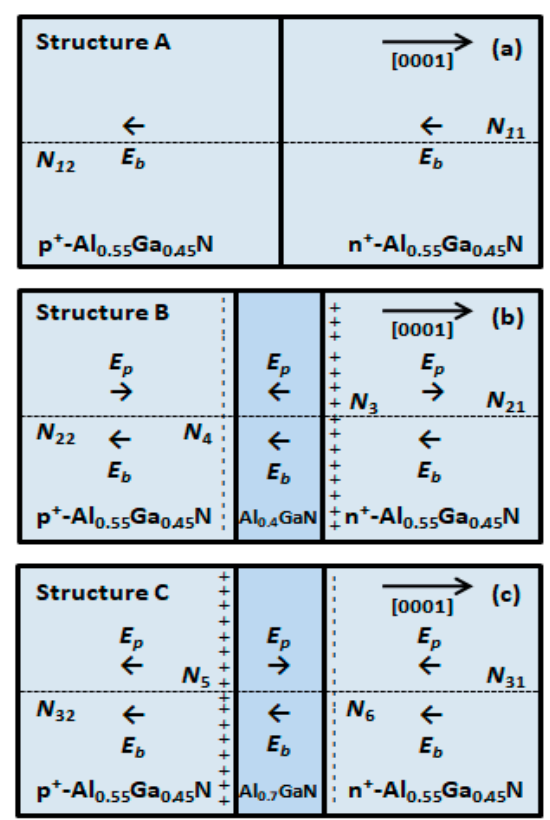
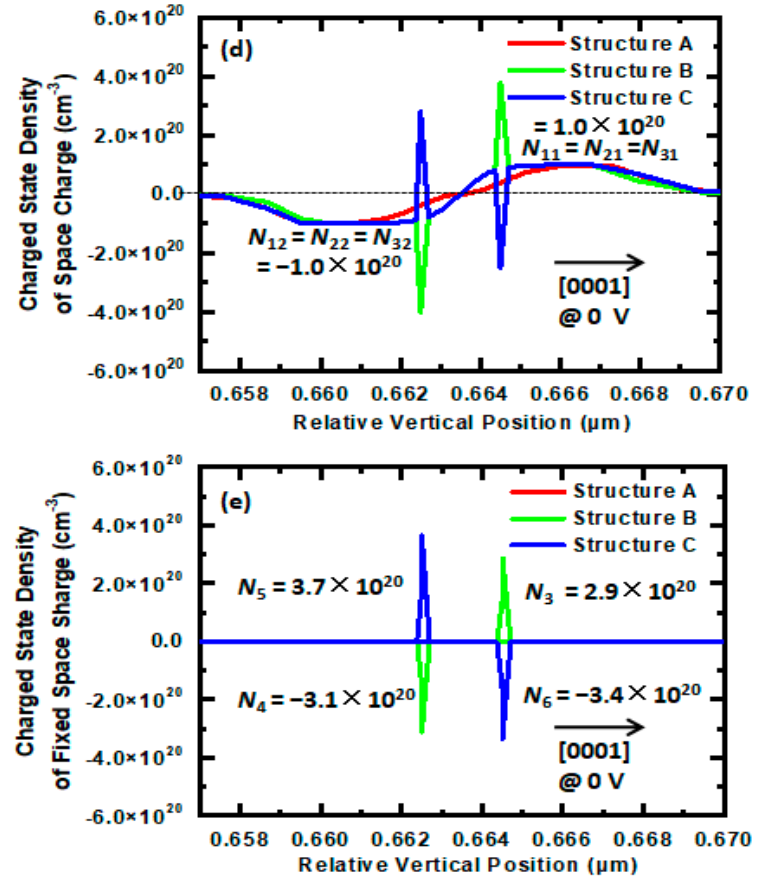

Figure 2. Distributions of the electric fields $(\mathbf{a}-\mathbf{c})$, the charged state densities of the space charges (d) and the charged state densities of the fixed space charges at the interfaces (e) in TJs in Structures $\mathrm{A}, \mathrm{B}$, and $\mathrm{C}$ at a bias voltage of $0 \mathrm{~V}$. $\mathrm{N}$ is the charged state density of the space charge.

For Structure $\mathrm{A}$, the $\mathrm{TJ}$ is a $\mathrm{p}^{+}-\mathrm{n}^{+}$homojunction and $E_{c}$ comes from the contribution of only $E_{b}$, as shown in Figure $2 a$. $E_{b}$ comes from the ionized dopant in the space charge region; has a direction along the [000-1] orientation, beginning with $N_{11}$ in the $\mathrm{n}^{+}-\mathrm{Al}_{0.55} \mathrm{Ga}_{0.45} \mathrm{~N}$ layer and ending with $N_{12}$ in the $\mathrm{p}^{+}-\mathrm{Al}_{0.55} \mathrm{Ga}_{0.45} \mathrm{~N}$ layer; and can be calculated as $N_{11}=1.0 \times 10^{20} \mathrm{~cm}^{-3}$ and $N_{12}=-1.0 \times 10^{20} \mathrm{~cm}^{-3}$, as shown in Figure $2 \mathrm{~d}$.

For Structure B, the PTJ is a $\mathrm{p}^{+}-\mathrm{i}-\mathrm{n}^{+}$heterojunction, and $E_{c}$ comes from the contributions of $E_{b}$ and $E_{p}$, as shown in Figure $2 \mathrm{~b}$. $E_{b}$ has a direction along the [000-1] orientation, beginning with $N_{21}$ in the $\mathrm{n}^{+}-\mathrm{Al}_{0.55} \mathrm{Ga}_{0.45} \mathrm{~N}$ layer and ending with $N_{22}$ in the $\mathrm{p}^{+}-\mathrm{Al}_{0.55} \mathrm{Ga}_{0.45} \mathrm{~N}$ layer, and it can be calculated as $N_{21}=1.0 \times 10^{20} \mathrm{~cm}^{-3}$ and $N_{22}=-1.0 \times 10^{20} \mathrm{~cm}^{-3}$, as shown in Figure $2 \mathrm{~d}$. $E_{p}$ is built up from the differences between $N_{3}$ at the $\mathrm{Al}_{0.4} \mathrm{Ga}_{0.6} \mathrm{~N} / \mathrm{n}^{+}-\mathrm{Al}_{0.55} \mathrm{Ga}_{0.45} \mathrm{~N}$ interface and $N_{4}$ at the $\mathrm{p}^{+}-\mathrm{Al}_{0.55} \mathrm{Ga}_{0.45} \mathrm{~N} / \mathrm{Al}_{0.4} \mathrm{Ga}_{0.6} \mathrm{~N}$ interface, where $N_{3}>0$ and $N_{4}<0$ under compressive strain of $\mathrm{Al}_{0.4} \mathrm{Ga}_{0.6} \mathrm{~N}$, and can be calculated as $N_{3}=2.9 \times 10^{20} \mathrm{~cm}^{-3}$ and $N_{4}=-3.1 \times 10^{20} \mathrm{~cm}^{-3}$, as shown in Figure 2e. $E_{p}$ has a direction along the [000-1] orientation in the $\mathrm{Al}_{0.4} \mathrm{Ga}_{0.6} \mathrm{~N}$ layer, in the same direction as $E_{b}$, and a direction along the [0001] orientation at both sides of the $\mathrm{Al}_{0.4} \mathrm{Ga}_{0.6} \mathrm{~N}$ layer, in the reverse direction to $E_{b}$, as shown in Figure $2 \mathrm{~b}$.

For Structure C, the PTJ is also a $\mathrm{p}^{+}-\mathrm{i}-\mathrm{n}^{+}$heterojunction, and $E_{c}$ also comes from the contributions of $E_{b}$ and $E_{p}$, as shown in Figure 2c. $E_{b}$ has a direction along the [000-1] orientation, beginning with $N_{31}$ in the $\mathrm{n}^{+}-\mathrm{Al}_{0.55} \mathrm{Ga}_{0.45} \mathrm{~N}$ layer and ending with $N_{32}$ in the $\mathrm{p}^{+}-\mathrm{Al}_{0.55} \mathrm{Ga}_{0.45} \mathrm{~N}$ layer, and can be calculated as $N_{31}=1.0 \times 10^{20} \mathrm{~cm}^{-3}$ and $N_{32}=-1.0 \times 10^{20} \mathrm{~cm}^{-3}$ as shown in Figure 2 d. $E_{p}$ is built up from the differences between $N_{5}$ at the $\mathrm{p}^{+}-\mathrm{Al}_{0.55} \mathrm{Ga}_{0.45} \mathrm{~N} / \mathrm{Al}_{0.7} \mathrm{Ga}_{0.3} \mathrm{~N}$ interface and $N_{6}$ at the $\mathrm{Al}_{0.7} \mathrm{Ga}_{0.3} \mathrm{~N} / \mathrm{n}^{+}-\mathrm{Al}_{0.55} \mathrm{Ga}_{0.45} \mathrm{~N}$ interface, where $N_{5}>0$ and $N_{6}<0$ under tensile strain of $\mathrm{Al}_{0.7} \mathrm{Ga}_{0.3} \mathrm{~N}$, and can be calculated as $N_{5}=3.7 \times 10^{20} \mathrm{~cm}^{-3}$ and $N_{6}=-3.4 \times 10^{20} \mathrm{~cm}^{-3}$, as shown in Figure 2e. $E_{p}$ has a direction along the [0001] orientation in the $\mathrm{Al}_{0.7} \mathrm{Ga}_{0.3} \mathrm{~N}$ layer, in the reverse direction to $E_{b}$, and a direction along the [000-1] orientation at both sides of the $\mathrm{Al}_{0.7} \mathrm{Ga}_{0.3} \mathrm{~N}$ layer, in the same direction as $E_{b}$, as shown in Figure 2c. 
Figure 3 compares the electric field profiles at a relative horizontal position of $100 \mu \mathrm{m}$ in the TJs of LEDs $\left(300 \times 300 \mu \mathrm{m}^{2}\right)$ for Structures A, B, and C at a current of $180 \mathrm{~mA}$. For all three structures, the intensities of $E_{c}$ were very strong in the TJ regions. For Structure A, $E_{c}$ comes from the contribution of only $E_{b}$ with a direction along the [000-1] orientation, as shown in Figure $2 \mathrm{a}$. For Structure $\mathrm{B}, E_{c}$ comes from the contributions of $E_{b}$ and $E_{p}$. $E_{b}$ has a direction along the [000-1] orientation. $E_{p}$ has a direction along the [000-1] orientation in the $\mathrm{Al}_{0.4} \mathrm{Ga}_{0.6} \mathrm{~N}$ layer, in the same direction as $E_{b}$, and a direction along the [0001] orientation in the $\mathrm{p}^{+}-\mathrm{Al}_{0.55} \mathrm{Ga}_{0.45} \mathrm{~N}$ and $\mathrm{n}^{+}-\mathrm{Al}_{0.55} \mathrm{Ga}_{0.45} \mathrm{~N}$ layers, in the reverse direction to $E_{b}$, as shown in Figure $2 \mathrm{~b}$. As a result, the intensity of $E_{c}$ is enhanced by $E_{p}$ in the $\mathrm{Al}_{0.4} \mathrm{Ga}_{0.6} \mathrm{~N}$ layer, and degraded by $E_{p}$ in the $\mathrm{p}^{+}-\mathrm{Al}_{0.55} \mathrm{Ga}_{0.45} \mathrm{~N}$ and $\mathrm{n}^{+}-\mathrm{Al}_{0.55} \mathrm{Ga}_{0.45} \mathrm{~N}$ layers compared with Structure A, as shown in Figure 3. For Structure C, $E_{c}$ comes from the contributions of $E_{b}$ and $E_{p} . E_{b}$ has a direction along the [000-1] orientation. $E_{p}$ has a direction along the [0001] orientation in the $\mathrm{Al}_{0.7} \mathrm{Ga}_{0.3} \mathrm{~N}$ layer, in the reverse direction to $E_{b}$, and a direction along the [000-1] orientation in the $\mathrm{p}^{+}-\mathrm{Al}_{0.55} \mathrm{Ga}_{0.45} \mathrm{~N}$ and $\mathrm{n}^{+}-\mathrm{Al}_{0.55} \mathrm{Ga}_{0.45} \mathrm{~N}$ layers, in the same direction as $E_{b}$, as shown in Figure 2c. As a result, the intensity of $E_{c}$ is degraded by $E_{p}$ in the $\mathrm{Al}_{0.7} \mathrm{Ga}_{0.3} \mathrm{~N}$ layer, and enhanced by $E_{p}$ in the $\mathrm{p}^{+}-\mathrm{Al}_{0.55} \mathrm{Ga}_{0.45} \mathrm{~N}$ and $\mathrm{n}^{+}-\mathrm{Al}_{0.55} \mathrm{Ga}_{0.45} \mathrm{~N}$ layers, as compared with Structure A, as shown in Figure 3.

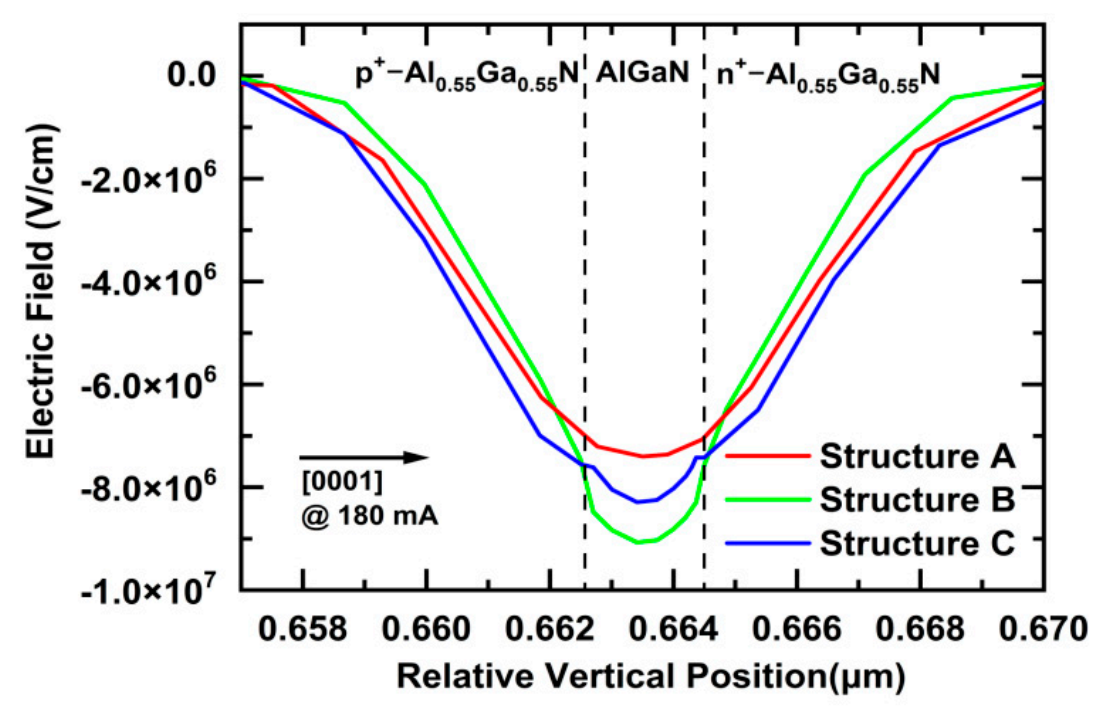

Figure 3. Comparison of the electric field profiles at a relative horizontal position of $100 \mu \mathrm{m}$ in the TJs of LEDs $\left(300 \times 300 \mu \mathrm{m}^{2}\right)$ in Structures A, B, and C at a current of $180 \mathrm{~mA}$.

Moreover, $\varepsilon_{r}$ has a role in controlling the intensity of $E_{c}$, according to the expression in Equation (1). For AlGaN, $\varepsilon_{r}$ becomes small with an increase in the Al content of AlGaN. For Structure $\mathrm{B}, \mathrm{Al}_{0.4} \mathrm{Ga}_{0.6} \mathrm{~N}$ as the dielectric layer has a higher $\varepsilon_{r}$ than Structure $\mathrm{A}$ with $\mathrm{Al}_{0.55} \mathrm{Ga}_{0.45} \mathrm{~N}$, which should have decreased the intensity of $E_{c}$. Nevertheless, an increased electric field is still obtained because of the contribution of a polarization-induced electric field in the center. For Structure $\mathrm{C}, \mathrm{Al}_{0.7} \mathrm{Ga}_{0.3} \mathrm{~N}$ as the dielectric layer has a lower $\varepsilon_{r}$ than Structure A with $\mathrm{Al}_{0.55} \mathrm{Ga}_{0.45} \mathrm{~N}$, which enhances the intensity of $E_{c}$ because of the contribution of $\varepsilon_{r}$ in the center. Thus, according to the final results regarding the contributions of $E_{b}, E_{p}$, and $\varepsilon_{r}$, the intensities of $E_{c}$ are in the following order: Structure B $>$ Structure $C>$ Structure A in the center peak, and Structure C > Structure A > Structure B at both sides of the center, as shown in Figure 3.

According to Figure 3, the calculated peak intensities of $E_{c}$ are as follows: $E_{A}=7.40$ $\times 10^{6} \mathrm{~V} / \mathrm{cm}, E_{B}=9.07 \times 10^{6} \mathrm{~V} / \mathrm{cm}$, and $E_{C}=8.24 \times 10^{6} \mathrm{~V} / \mathrm{cm}$ for Structures A, B, and $C$ in the center peak, respectively. This means that very strong electric field intensities are generated in the TJ regions of the LEDs in Structures A, B, and C. Driven by $E_{c}$, the electrons in the valence band of the $\mathrm{p}^{+}-\mathrm{Al}_{0.55} \mathrm{Ga}_{0.45} \mathrm{~N}$ layer can tunnel through the TJ and inject themselves into the conduction band of the $\mathrm{n}^{+}-\mathrm{Al}_{0.55} \mathrm{Ga}_{0.45} \mathrm{~N}$ layer. The holes are 
simultaneously generated in the valence band of the $\mathrm{p}^{+}-\mathrm{Al}_{0.55} \mathrm{Ga}_{0.45} \mathrm{~N}$ layer, and then injected into the MQWs of the LEDs.

Figure 4 shows a comparison of the energy-band profiles at a relative horizontal position of $100 \mu \mathrm{m}$ in the TJs of LEDs $\left(300 \times 300 \mu \mathrm{m}^{2}\right)$ for Structures A, B, and C, at a current of $180 \mathrm{~mA}$. For Structures A, B, and C, the conduction bands of $\mathrm{n}^{+}-\mathrm{Al}_{0.55} \mathrm{Ga}_{0.45} \mathrm{~N}\left(\mathrm{n}^{+}=1 \times 10^{20} \mathrm{~cm}^{-3}\right)$ align well below the valence bands of $\mathrm{p}^{+}-\mathrm{Al}_{0.55} \mathrm{Ga}_{0.45} \mathrm{~N}\left(\mathrm{p}^{+}=1 \times 10^{20} \mathrm{~cm}^{-3}\right)$. When the LEDs are operated at a forward biased voltage, the top TJs are operated at a reverse biased voltage, so the electrons can tunnel from the $\mathrm{p}^{+}$-side valence band into the $\mathrm{n}^{+}$-side conduction band, and the holes are simultaneously generated in the p-type layer. Under the reverse biased voltage, the conduction band levels in the TJs are totally different. The $\mathrm{n}^{+}$-side conduction band levels are in the following order: Structure B $>$ Structure A $>$ Structure C. The widths of the TJs in Structures A, B, and C are the distances between Positions $\mathrm{O}$ and $\mathrm{A}$, Positions $\mathrm{O}$ and $\mathrm{B}$, and Positions $\mathrm{O}$ and $\mathrm{C}$, respectively. The calculated widths of the TJs are as follows: $|\mathrm{OA}|=8.9 \mathrm{~nm},|\mathrm{OB}|=9.5 \mathrm{~nm}$, and $|\mathrm{OC}|=8.0 \mathrm{~nm}$. The widths of the TJs for Structures A, $B$, and $C$ are in the following order: Structure $B>$ Structure A $>$ Structure $C$. The short width of the PTJ in Structure $C$ can counteract the large energy barrier, and may help to enhance the tunneling probabilities of the electrons in the PTJ.

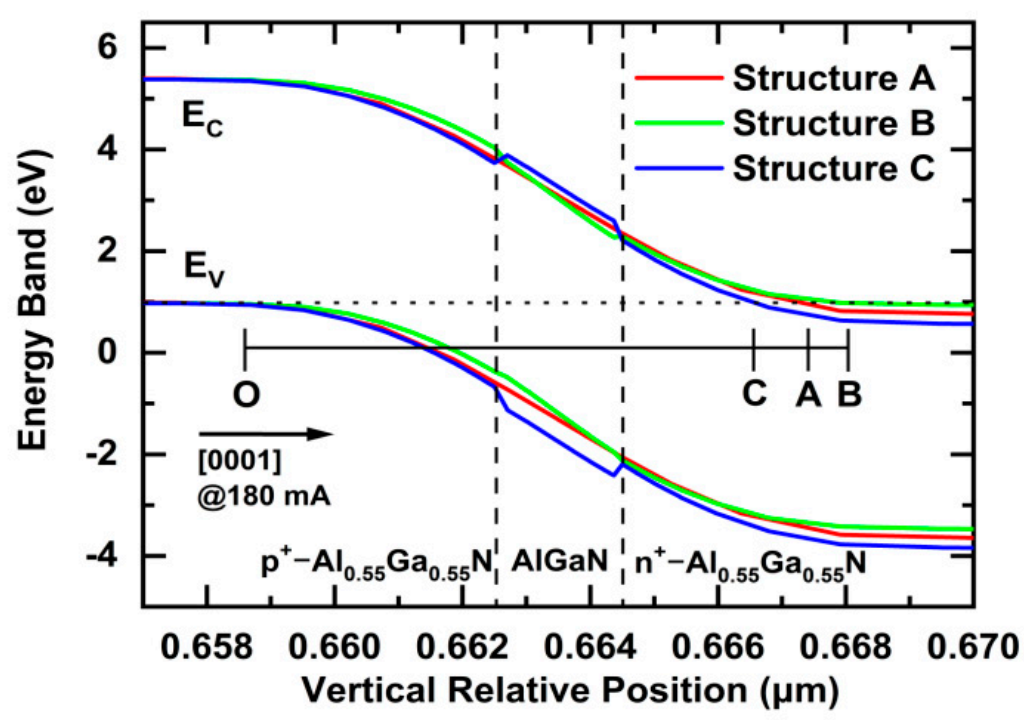

Figure 4. Comparisons of the energy band profiles at a relative horizontal position of $100 \mu \mathrm{m}$ in the TJs of LEDs $\left(300 \times 300 \mu \mathrm{m}^{2}\right)$ in Structures A, B, and C at a current of $180 \mathrm{~mA}$.

Figure 5 a shows a comparison of the hole concentration distributions along the vertical direction at a relative horizontal position of $100 \mu \mathrm{m}$ in the MQWs of the LEDs for Structures $\mathrm{A}, \mathrm{B}$, and C, at a current of $180 \mathrm{~mA}$. The hole concentrations along the vertical direction in the MQWs are in the following order: Structure C > Structure A > Structure B. The high hole concentration in the MQWs in Structure $C$ comes from the enhanced lateral current spreading in the PTJ.

Figure $5 \mathrm{~b}$ shows a comparison of the radiative recombination rates along the vertical direction at a relative horizontal position of $100 \mu \mathrm{m}$ in the MQWs of the LEDs for Structures $\mathrm{A}, \mathrm{B}$, and $\mathrm{C}$ at a current of $180 \mathrm{~mA}$. The radiative recombination rates along the vertical direction in the MQWs are in the following order: Structure C > Structure A > Structure B. The radiative recombination rates come from the contributions of the high electron and hole concentrations in the MQWs, as is consistent with the hole-concentration distributions in the MQWs, as shown in Figure 5a. 

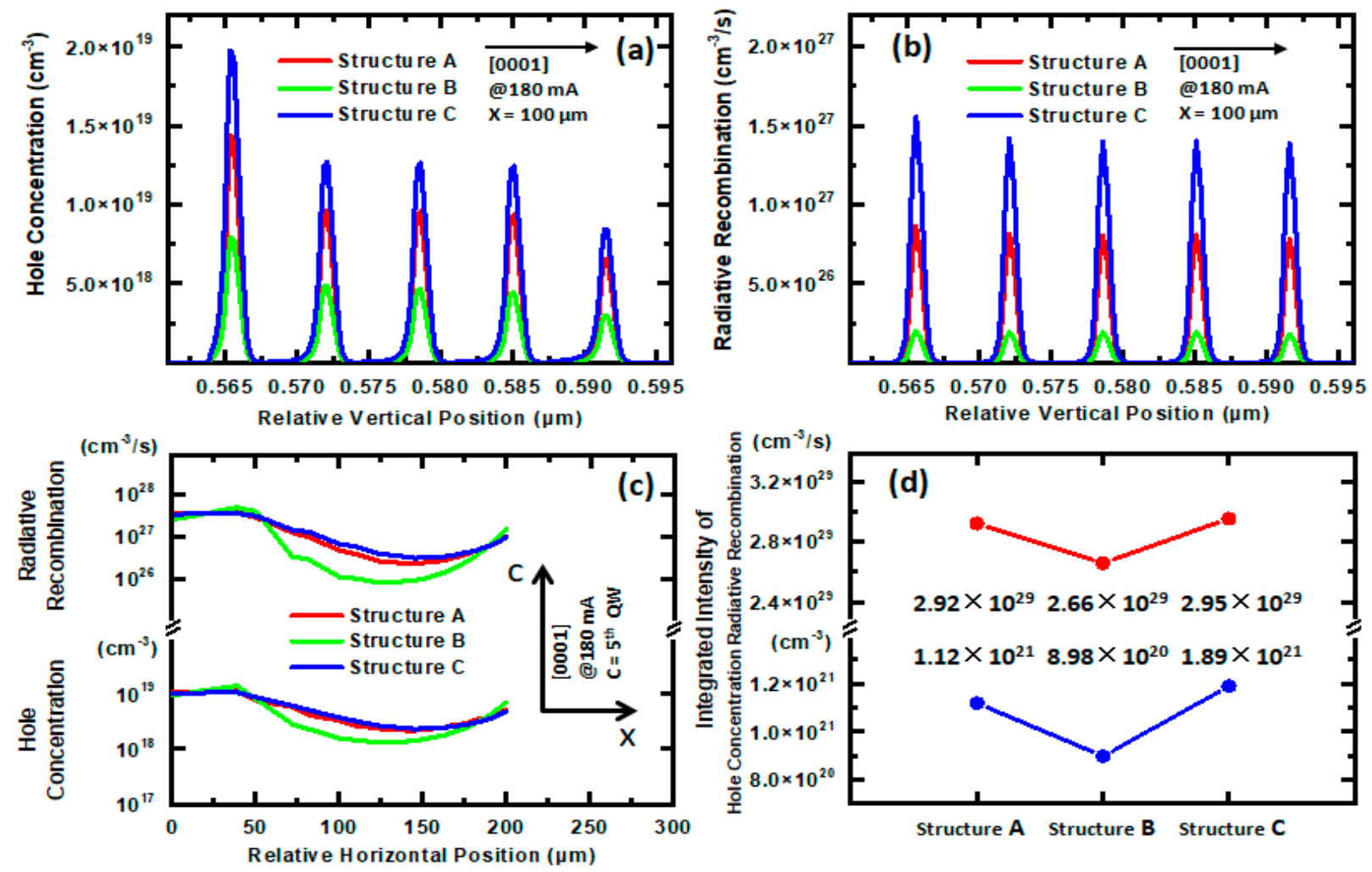

Figure 5. (a) Hole concentrations and (b) radiative recombination rates in the MQWs. (c) Lateral distributions of the hole concentrations and radiative recombination rates along the horizontal direction (x-axis) in MQWs. (d) Integrated values of lateral hole concentrations and lateral radiative recombination rates at the relative horizontal positions between 0 and $200 \mu \mathrm{m}$ for Structures A, B, and C at a current of $180 \mathrm{~mA}$.

In order to investigate the effects of the TJs on the current spreading in LEDs, the lateral distributions of the hole concentrations and the radiative recombination rates along the horizontal direction (x-axis) in the LEDs were characterized. Figure $5 \mathrm{c}$ shows a comparison of the lateral distributions of the hole concentrations and the radiative recombination rates along the horizontal direction ( $\mathrm{x}$-axis) and at a relative vertical position of the fifth QW (c-axis) in LEDs for Structures A, B, and C. For Structure B, the lateral distributions of the hole concentrations and the radiative recombination rates along the horizontal direction in the LEDs are very non-uniform: high at the horizontal positions of $0 \sim 50 \mu \mathrm{m}$, which is just below the anode, and low at the positions of $50 \sim 200 \mu \mathrm{m}$. This means that the positions under the anode are the main current flow paths going through the MQWs, which will cause current crowding and Joule heat. For Structures A, B, and C, the lateral distribution uniformities of the hole concentrations and the radiative recombination rates along the horizontal direction (x-axis) in the LEDs are in the following order: Structure $C>$ Structure A > Structure B. The uniformities come from the contributions of high resistance in the TJs. If we compare Structures A, B, and C, the tunneling probability of electrons and the $\mathrm{Al}$ content of $\mathrm{AlGaN}$ in the TJs determine the resistance. Structure $\mathrm{C}$ has a lower electron tunneling probability and a higher $\mathrm{Al}$ content of $\mathrm{AlGaN}$ in the PTJ than Structure B, thus resulting in the higher resistance of the PTJ in Structure C. Therefore, Structure $\mathrm{C}$ with $\mathrm{Al}_{0.7} \mathrm{Ga}_{0.3} \mathrm{~N}$ as the dielectric layer has higher uniformity than Structure $\mathrm{B}$ with $\mathrm{Al}_{0.4} \mathrm{Ga}_{0.6} \mathrm{~N}$ as the dielectric layer, which means that relatively higher resistance of the TJ has a meaningful impact on the current spreading of an LED.

In order to quantitatively compare the lateral distribution uniformities of the hole concentrations and radiative recombination rates on the output characteristics of the LEDs for Structures A, B, and C, the integrated intensities of the lateral distributions of the hole concentrations and radiative recombination rates at the relative horizontal 
positions between 0 and $200 \mu \mathrm{m}$ were characterized. Figure $5 \mathrm{~d}$ shows a comparison of the integrated intensities of the lateral distributions of the hole concentrations and radiative recombination rates along the horizontal direction ( $x$-axis) and at a relative vertical position of the fifth QW (c-axis) in LEDs for Structures A, B, and C. The integrated intensities for both the hole concentrations and radiative recombination rates are in the following order: Structure C > Structure A > Structure B. Compared with the lateral distributions of the hole concentrations and radiative recombination rates along the horizontal direction (x-axis), the integrated intensities more accurately reflected the output characteristics of LEDs with the different structures.

Figure 6 shows a comparison of the output current-voltage $(I-V)$ characteristics of the LEDs $\left(300 \times 300 \mu \mathrm{m}^{2}\right)$ for Structures A, B, and C. The forward voltages of the LEDs are in the following order: Structure $C>$ Structure A $>$ Structure B. When an LED is operated at a forward biased voltage, the top TJ is operated at a reverse biased voltage. A TJ operating at a reverse biased voltage can be treated as a resistor, and its resistance determines the forward voltage of the LED, so that the forward voltage of an LED increases with an increase in the resistance of the JT. If we compare Structures A, B, and C, the tunneling probability of electrons and the $\mathrm{Al}$ content of $\mathrm{AlGaN}$ in the TJs determine the resistance, and the resistance determines the forward voltage of the LED. The resistances of the TJs are in the following order: Structure C > Structure A > Structure B, so the forward voltages of the LEDs are in the following order: Structure $C>$ Structure A $>$ Structure B. This indicates that the TJ has a nonnegligible impact on the forward voltage of DUV LEDs, and much higher biased voltage is required to realize higher tunneling efficiency for Structure $C$ with a higher $\mathrm{Al}$ content of AlGaN.

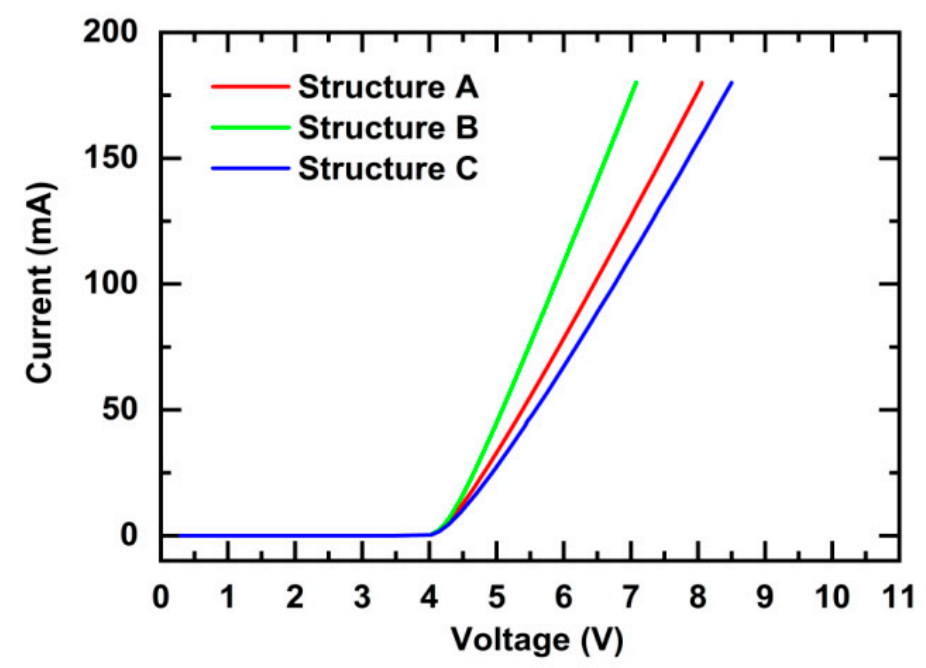

Figure 6. Comparison of the output $I-V$ characteristics of LEDs $\left(300 \times 300 \mu \mathrm{m}^{2}\right)$ for Structures A, B, and $C$.

Figure 7a shows a comparison of the IQE and optical output power of the LEDs $\left(300 \times 300 \mu \mathrm{m}^{2}\right)$ for Structures A, B, and C. Both the IQE and the optical output power of the LEDs are in the following order: Structure C > Structure A > Structure B, consistent with the results shown in Figure 5d, and inditcating that the enhanced IQE and optical output power of the LED for Structure $C$ were achieved. Figure $7 \mathrm{~b}$ shows a comparison of the WPE of LEDs for Structures A, B, and C. The WPE of the LEDs is in the following order: Structure $\mathrm{B}>$ Structure A $>$ Structure C. The WPE is inversely proportional to the forward voltage, so the LED for Structure $C$ had the lowest WPE due to the highest forward voltage. 

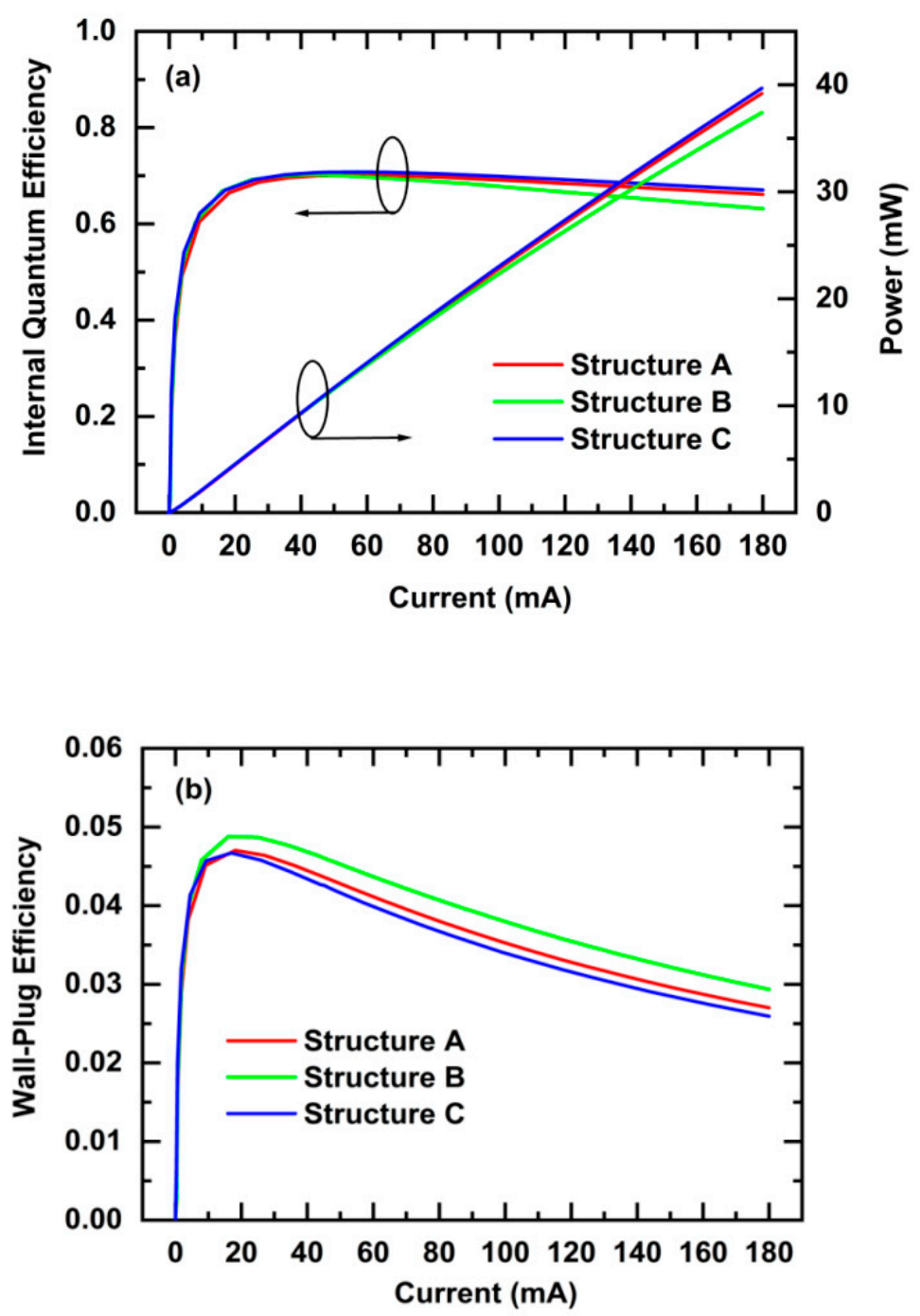

Figure 7. Comparison of the IQE and optical output power (a) and the WPE (b) of the LEDs $\left(300 \times 300 \mu \mathrm{m}^{2}\right)$ for Structures A, B, and C.

\section{Conclusions}

AlGaN-based DUV LEDs with AlGaN as the dielectric layers in $\mathrm{p}^{+}-\mathrm{Al}_{0.55} \mathrm{Ga}_{0.45} \mathrm{~N} / \mathrm{AlGaN} /$ $\mathrm{n}^{+}-\mathrm{Al}_{0.55} \mathrm{Ga}_{0.45} \mathrm{~N}$ PTJs were proposed for promoting carrier tunneling, suppressing current crowding, avoiding optical absorption, and further enhancing the performance of LEDs. $\mathrm{Al}_{0.7} \mathrm{Ga}_{0.3} \mathrm{~N}$ with a lower dielectric constant can realize a higher hole concentration and a higher radiative recombination rate in $\mathrm{MQWs}$ than $\mathrm{Al}_{0.4} \mathrm{Ga}_{0.6} \mathrm{~N}$ with a higher dielectric constant. The high hole concentration and high radiative recombination rate in MQWs come from enhanced lateral current spreading in the LED. Moreover, besides the high electrically conductive $\mathrm{n}^{+}-\mathrm{Al}_{0.55} \mathrm{Ga}_{0.45} \mathrm{~N}$ layer in the PTJ, $\mathrm{Al}_{0.7} \mathrm{Ga}_{0.3} \mathrm{~N}$ as the dielectric layer has relatively high resistance, which can increase the lateral current spreading and enhance the uniformity of the top emitting light of AlGaN-based DUV LEDs. As a result, the IQE and optical output power can be enhanced. However, its relatively high resistance results in an increase in the forward voltage, which is disadvantageous to the WPE. Through the adoption of PTJ with $\mathrm{Al}_{0.7} \mathrm{Ga}_{0.3} \mathrm{~N}$ as the dielectric layers, enhanced IQE and optical output power can be achieved. It is strongly believed that the proposed structure is promising for further improving the IQEs of DUV LEDs, and the physics of the reported device is also useful for better understanding the carrier tunnel, transport and recombination mechanisms of DUV LEDs. 
Author Contributions: Conceptualization, Y.W. and Z.Z.; methodology, Y.W., L.G. and Y.C.; software, L.G. and Y.C.; investigation, Y.L., Z.Q. and J.B.; writing-original draft, Y.W.; writing-review and editing, Z.Z. and X.S.; supervision, X.S. and D.L. All authors have read and agreed to the published version of the manuscript.

Funding: This research was funded by National Natural Science Foundation for Distinguished Young Scholars of China, grant number 61725403; National Natural Science Foundation of China, grant number 61922078, 61827813, 62004196, 62074050, and 61774025; Youth Innovation Promotion Association of the Chinese Academy of Sciences, grant number Y201945; Youth Talent Promotion Project of the Chinese Institute of Electronics, grant number 2020QNRC001; Key-Area Research and Development Program of Suzhou Institute of Nano-Tech and Nano-Bionics, grant number 20YZ10.

Data Availability Statement: The data presented in this study are available on request from the corresponding author.

Conflicts of Interest: The authors declare no conflict of interest.

\section{References}

1. Li, D.B.; Jiang, K.; Sun, X.J.; Guo, C.L. AlGaN photonics: Recent advances in materials and ultraviolet devices. Adv. Opt. Photonics 2018, 10, 43-110. [CrossRef]

2. Taniyasu, Y.; Kasu, M.; Makimoto, T. An aluminum nitride light emitting diode with a wavelength of 210 nanometres. Nature 2006, 441, 325-328. [CrossRef]

3. Takano, T.; Mino, T.; Sakai, J.; Noguchi, N.; Tsubaki, K.; Hirayama, H. Deep ultraviolet light-emitting diodes with external quantum efficiency higher than $20 \%$ at $275 \mathrm{~nm}$ achieved by improving light-extraction efficiency. Appl. Phys. Express 2017, 10 031002. [CrossRef]

4. Kojima, K.; Nagasawa, Y.; Hirano, A.; Ippommatsu, M.; Honda, Y.; Amano, H.; Akasaki, I.; Chichibu, S.F. Carrier localization structure combined with current micropaths in AlGaN quantum wells grown on an AlN template with macrosteps. Appl. Phys. Lett. 2019, 114, 011102. [CrossRef]

5. Yang, W.; Li, D.; Liu, N.Y.; Chen, Z.; Wang, L.; Liu, L.; Li, L.; Wan, C.H.; Chen, W.H.; Hu, X.D.; et al. Improvement of hole injection and electron overflow by a tapered AlGaN electron blocking layer in InGaN-based blue laser diodes. Appl. Phys. Lett. 2012, 100, 031105. [CrossRef]

6. Santi, C.D.; Meneghini, M.; Monti, D.; Glaab, J.; Guttmann, M.; Rass, J.; Einfeldt, S.; Mehnke, F.; Enslin, J.; Wernicke, T.; et al. Recombination mechanisms and thermal droop in AlGaN-based UV-B LEDs. Photonics Res. 2017, 5, A44-A51. [CrossRef]

7. Yun, J.; Hirayama, H. Investigation of the light-extraction efficiency in 280nm AlGaN-based light-emitting diodes having a highly transparent p-AlGaN layer. J. Appl. Phys. 2017, 121, 013105. [CrossRef]

8. Hou, M.J.; Qin, Z.X.; He, C.G.; Cai, J.A.; Wang, X.Q.; Shen, B. Effect of injection current on the optical polarization of AlGaN-based ultraviolet light emitting diodes. Opt. Express 2014, 22, 19589-19594. [CrossRef]

9. Guo, Y.N.; Zhang, Y.; Yan, J.C.; Xie, H.Z.; Liu, L.; Chen, X.; Hou, M.J.; Qin, Z.X.; Wang, J.X.; Li, J.M. Light extraction enhancement of AlGaN-based ultraviolet light-emitting diodes by substrate sidewall roughening. Appl. Phys. Lett. 2017, 111, 011102. [CrossRef]

10. Jiang, K.; Sun, X.J.; Shi, Z.M.; Zang, H.; Ben, J.W.; Deng, H.X.; Li, D.B. Quantum engineering of nonequilibrium efficient p-doping in ultra-wide band-gap nitrides. Light-Sci. Appl. 2021, 10, 69. [CrossRef] [PubMed]

11. Nam, K.B.; Nakarmi, M.L.; Li, J.; Lin, J.Y.; Jiang, H.X. Mg acceptor level in AlN probed by deep ultraviolet photoluminescence. Appl. Phys. Lett. 2003, 83, 878-880. [CrossRef]

12. Edwards, J.; Kawabe, K.; Stevens, G.; Tredgold, R.H. Space charge conduction and electrical behaviour of aluminium nitride single crystals. Solid State Commun. 1965, 3, 99-100. [CrossRef]

13. Chin, V.W.L.; Tansley, T.L.; Osotchan, T. Electron mobilities in gallium, indium, and aluminum nitrides. J. Appl. Phys. 1994, 75 , 7365-7372. [CrossRef]

14. Chu, C.S.; Tian, K.K.; Che, J.M.; Shao, H.; Kou, J.Q.; Zhang, Y.H.; Zhang, Z.H.; Kuo, H.C. On the Impact of Electron Leakage on the Efficiency Droop for AlGaN Based Deep Ultraviolet Light Emitting Diodes. IEEE Photonics J. 2020, 12, 1600207. [CrossRef]

15. Lang, J.; Xu, F.J.; Ge, W.K.; Liu, B.Y.; Zhang, N.; Sun, Y.H.; Wang, J.M.; Wang, M.X.; Xie, N.; Fang, X.Z.; et al. Greatly enhanced performance of $\mathrm{AlGaN}$ based deep ultraviolet light emitting diodes by introducing a polarization modulated electron blocking layer. Opt. Express 2019, 27, A1458-A1466. [CrossRef]

16. Lang, J.; Xu, J.; Ge, W.K.; Liu, B.Y.; Zhang, N.; Sun, Y.H.; Wang, M.X.; Xie, N.; Fang, X.Z.; Kang, X.N.; et al. High performance of AlGaN deep-ultraviolet light emitting diodes due to improved vertical carrier transport by delta-accelerating quantum barriers. Appl. Phys. Lett. 2019, 114, 172105. [CrossRef]

17. Lu, L.; Zhang, Y.; Xu, F.J.; Ding, G.G.; Liu, Y.H. Performance improvement of AlGaN-based deep-ultraviolet light-emitting diodes via Al-composition graded quantum wells. Superlattices Microstruct. 2018, 118, 55-60. [CrossRef]

18. Xing, C.; Yu, H.B.; Ren, Z.J.; Zhang, H.C.; Dai, J.N.; Chen, C.Q.; Sun, H.D. Performance Improvement of AlGaN-Based Deep Ultraviolet Light-Emitting Diodes with Step-Like Quantum Barriers. IEEE J. Quantum Electron. 2020, 56, 3300106. [CrossRef] 
19. Mondal, R.K.; Chatterjee, V.; Pal, S. Effect of Step-graded Superlattice Electron Blocking Layer on performance of AlGaN based deep-UV light emitting diodes. Physica E Low Dimens. Syst. Nanostruct. 2019, 108, 233-237. [CrossRef]

20. Ye, D.Q.; Zhang, D.Y.; Wu, C.Y.; Wang, D.X.; Xu, C.K.; Zhang, J.; Huang, M.C. Using a compositionally step graded hole reservoir layer with hole accelerating ability for reducing efficiency droop in GaN-based LEDs. AIP Adv. 2017, 7, 055016. [CrossRef]

21. Yu, C.T.; Lai, W.C.; Yen, C.H.; Chang, S.J. Effects of InGaN layer thickness of AlGaN/InGaN superlattice electron blocking layer on the overall efficiency and efficiency droops of GaN-based light emitting diodes. Opt. Express 2014, 22, A663-A670. [CrossRef] [PubMed]

22. Lin, B.C.; Chen, K.J.; Wang, C.H.; Chiu, C.H.; Lan, Y.P.; Lin, C.C.; Lee, P.T.; Shih, M.H.; Kuo, Y.K.; Kuo, H.C. Hole injection and electron overflow improvement in InGaN/GaN light-emitting diodes by a tapered AlGaN electron blocking layer. Opt. Express 2014, 22, 463-469. [CrossRef] [PubMed]

23. Kwon, M.R.; Park, T.H.; Lee, T.H.; Lee, B.R.; Kim, T.G. Improving the performance of AlGaN-based deep-ultraviolet light-emitting diodes using electron blocking layer with a heart-shaped graded Al composition. Superlattices Microstruct. 2018, 116, 215-220. [CrossRef]

24. Lin, R.M.; Lu, Y.C.; Chou, Y.L.; Chen, G.H.; Lin, Y.H.; Wu, M.C. Enhanced characteristics of blue InGaN/GaN light-emitting diodes by using selective activation to modulate the lateral current spreading length. Appl. Phys. Lett. 2008, 92, 261105. [CrossRef]

25. Malyutenko, V.K.; Bolgov, S.S.; Tykhonov, A.N. Research on Electrical Efficiency Degradation Influenced by Current Crowding in Vertical Blue InGaN-on-SiC Light-Emitting Diodes. IEEE Photonics Technol. Lett. 2012, 24, 1124-1126. [CrossRef]

26. Li, C.K.; Wu, Y.R. Study on the Current Spreading Effect and Light Extraction Enhancement of Vertical GaN/InGaN LEDs. IEEE Trans. Electron Devices 2012, 59, 400-407. [CrossRef]

27. Zhang, Z.H.; Tan, S.T.; Liu, W.; Ju, Z.G.; Zheng, K.; Kyaw, Z.B.; Ji, Y.; Hasanov, N.; Sun, X.W.; Demir, H.V. Improved InGaN/GaN light-emitting diodes with a p-GaN/n-GaN/p-GaN/n-GaN/p-GaN current spreading layer. Opt. Express 2013, 21, 4958-4969. [CrossRef] [PubMed]

28. Horng, R.H.; Chen, K.Y.; Tien, C.H.; Liao, J.C. Effects of Mesa Size on Current Spreading and Light Extraction of GaN-Based LED. J. Disp. Technol. 2015, 11, 1010-1013. [CrossRef]

29. Takehara, K.; Takeda, K.; Nagata, K.; Sakurai, H.; Ito, S.; Iwaya, M.; Takeuchi, T.; Kamiyama, S.; Akasaki, I.; Amano, H. Transparent electrode for UV light-emitting-diodes. Phys. Status Solidi C 2011, 8, 2375-2377. [CrossRef]

30. Takeuchi, T.; Hasnain, G.; Corzine, S.; Hueschen, M.; Schneider, R.P., Jr.; Kocot, C.; Blomqvist, M.; Chang, Y.L.; Lefforge, D.; Krames, M.R.; et al. GaN-Based Light Emitting Diodes with Tunnel Junctions. Jpn. J. Appl. Phys. 2001, 40, L861-L863. [CrossRef]

31. Jeon, S.R.; Song, Y.H.; Jang, H.J.; Yanga, G.M. Lateral current spreading in GaN-based light-emitting diodes utilizing tunnel contact junctions. Appl. Phys. Lett. 2001, 78, 3265-3267. [CrossRef]

32. Jeon, S.R.; Song, Y.H.; Jang, H.J.; Kim, K.S.; Yang, G.M.; Hwang, S.W.; Son, S.J. Buried Tunnel Contact Junctions in GaN-Based Light-Emitting Diodes. Phys. Status Solidi A 2001, 188, 167-170. [CrossRef]

33. Jeon, S.R.; Cho, M.S.; Yu, M.A.; Yang, G.M. GaN-Based Light-Emitting Diodes Using Tunnel Junctions. IEEE J. Sel. Top. Quantum Electron. 2002, 8, 739-743. [CrossRef]

34. Lee, C.M.; Chuo, C.C.; Chen, I.L.; Chang, J.C.; Chyi, J.I. High-brightness inverted InGaN-GaN multiple-quantum-well lightemitting diodes without a transparent conductive layer. IEEE Electron Device Lett. 2003, 24, 156-158.

35. Zhang, Z.H.; Tan, S.T.; Kyaw, Z.; Ji, Y.; Liu, W.; Ju, Z.G.; Hasanov, N.; Sun, X.W.; Demir, H.V. InGaN/GaN light-emitting diode with a polarization tunnel junction. Appl. Phys. Lett. 2013, 102, 193508. [CrossRef]

36. Li, L.P.; Zhang, Y.H.; Tian, K.K.; Chu, C.S.; Fang, M.Q.; Meng, R.L.; Shi, Q.; Zhang, Z.H.; Bi, W.G. Numerical Investigations on the $\mathrm{n}+-\mathrm{GaN} / \mathrm{AlGaN} / \mathrm{p}+-\mathrm{GaN}$ Tunnel Junction for III-Nitride UV Light-Emitting Diodes. Phys. Status Solidi A 2017, $214,1700624$. [CrossRef]

37. Li, L.P.; Shi, Q.; Tian, K.K.; Chu, C.S.; Fang, M.Q.; Meng, R.L.; Zhang, Y.H.; Zhang, Z.H.; Bi, W.G. A dielectric-constant-controlled tunnel junction for III-nitride light-emitting diodes. Phys. Status Solidi A 2017, 214, 1600937. [CrossRef]

38. Zhang, Y.W.; Krishnamoorthy, S.; Johnson, J.M.; Akyol, F.; Allerman, A.; Moseley, M.W.; Armstrong, A.; Hwang, J.; Rajan, S. Interband tunneling for hole injection in III-nitride ultraviolet emitters. Appl. Phys. Lett. 2015, 106, 141103. [CrossRef]

39. Zhang, Y.W.; Krishnamoorthy, S.; Akyol, F.; Allerman, A.A.; Moseley, M.W.; Armstrong, A.M.; Rajan, S. Design and demonstration of ultra-wide bandgap AlGaN tunnel junctions. Appl. Phys. Lett. 2016, 109, 121102. [CrossRef]

40. Zhang, Y.W.; Jamal-Eddine, Z.; Akyol, F.; Bajaj, S.; Johnson, J.M.; Calderon, G.; Allerman, A.A.; Moseley, M.W.; Armstrong, A.M.; Hwang, J.; et al. Tunnel-injected sub $290 \mathrm{~nm}$ ultra-violet light emitting diodes with $2.8 \%$ external quantum efficiency. Appl. Phys. Lett. 2018, 112, 071107. [CrossRef]

41. Pandey, A.; Gim, J.; Hovden, R.; Mi, Z. Electron overflow of AlGaN deep ultraviolet light emitting diodes. Appl. Phys. Lett. 2021, 118, 241109. [CrossRef]

42. Ozden, I.; Makarona, E.; Nurmikko, A.V.; Takeuchi, T.; Krames, M. A dual-wavelength indium gallium nitride quantum well light emitting diode. Appl. Phys. Lett. 2001, 79, 2532-2534. [CrossRef]

43. Grundmann, M.J.; Mishra, U.K. Multi-color light emitting diode using polarization-induced tunnel junctions. Phys. Status Solidi C 2007, 4, 2830-2833. [CrossRef]

44. Malinverni, M.; Martin, D.; Grandjean, N. InGaN based micro light emitting diodes featuring a buried GaN tunnel junction. Appl. Phys. Lett. 2015, 107, 051107. [CrossRef] 
45. Okawara, S.; Aoki, Y.; Kuwabara, M.; Takagi, Y.; Maeda, J.; Yoshida, H. Nitride-based stacked laser diodes with a tunnel junction. Appl. Phys. Express 2018, 11, 012701. [CrossRef]

46. Fiorentini, V.; Bernardini, F.; Ambacher, O. Evidence for nonlinear macroscopic polarization in III-V nitride alloy heterostructures. Appl. Phys. Lett. 2002, 80, 1204. [CrossRef]

47. Meneghini, M.; Trivellin, N.; Meneghesso, G.; Zanoni, E.; Zehnder, U.; Hahn, B. A combined electro-optical method for the determination of the recombination parameters in InGaN-based light-emitting diodes. J. Appl. Phys. 2009, 106, 114508. [CrossRef]

48. Laubsch, A.; Sabathil, M.; Bergbauer, W.; Strassburg, M.; Lugauer, H.; Peter, M.; Lutgen, S.; Linder, N.; Streubel, K.; Hader, J.; et al. On the origin of IQE-'droop' in InGaN LEDs. Phys. Status Solidi C 2009, 6, S913-S916. [CrossRef]

49. Piprek, J.; Li, S. Electron leakage effects on GaN-based light-emitting diodes. Opt. Quantum Electron. 2011, 42, 89-95. [CrossRef]

50. Zhang, L.; Ding, K.; Liu, N.X.; Wei, T.B.; Ji, X.L.; Ma, P.; Yan, J.C.; Wang, J.X.; Zeng, Y.P.; Li, J.M. Theoretical study of polarizationdoped GaN-based light-emitting diodes. Appl. Phys. Lett. 2011, 98, 101110. [CrossRef]

51. Piprek, J. Efficiency droop in nitride-based light-emitting diodes. Phys. Status Solidi A 2010, 207, 2217-2225. [CrossRef]

52. Zhang, Z.H.; Liu, W.; Tan, S.T.; Ji, Y.; Wang, L.C.; Zhu, B.B.; Zhang, Y.P.; Lu, S.P.; Zhang, X.L.; Hasanov, N.; et al. A hole accelerator for InGaN/GaN light-emitting diodes. Appl, Phys. Lett. 2014, 105, 153503. [CrossRef]

53. Zhang, Z.H.; Zhang, Y.H.; Bi, W.G.; Geng, C.; Xu, S.; Demir, H.V.; Sun, X.W. A charge inverter for III-nitride light-emitting diodes. Appl. Phys. Lett. 2016, 108, 133502. [CrossRef]

54. Suzuki, M.; Uenoyama, T.; Yanase, A. First-principles calculations of effective-mass parameters of AlN and GaN. Phys. Rev. B 1995, 52, 8132-8139. [CrossRef]

55. Vurgaftman, I.; Meyer, J.R. Band parameters for nitrogen-containing semiconductors. J. Appl. Phys. 2003, 94, 3675-3696. [CrossRef] 